O Cooperativismo como vantagem Competitiva: Uma Análise entre as Sociedades Cooperativas e os Bancos Comerciais

Ana Carolina C. L. da Silva / Ana Paula Ferreira da Costa

Artigo de Demanda Contínua

\title{
O Cooperativismo como Vantagem Competitiva: \\ Uma Análise entre as Sociedades Cooperativas e os Bancos Comerciais
}

\author{
Ana Carolina C. L. da Silva \\ Universidade Severino Sombra, Centro de Letras, Ciências Socais \\ Aplicadas e Humanas, Curso de Bacharel em Administração, \\ anac.calegaro@gmail.com

\begin{abstract}
Universidade Severino Sombra, Centro de Letras, Ciências Socais Aplicadas e Humanas, Curso de Bacharel em Administração, anapaula@cremendes.com.br
\end{abstract} \\ Ana Paula Ferreira da Costa
}

\begin{abstract}
Resumo: Atualmente a sociedade passa por transformações constantes de cunho social, econômico e político em razão do processo de globalização em que estamos inseridos. Com isso a competitividade entre os mercados se torna ainda mais acirrada. Dentro do mercado financeiro existem duas formas de sociedades oferecendo os mesmos produtos e serviços, porém com perfis bem diferentes: as sociedades cooperativas focando no bem estar social e no capital humano e os bancos comerciais visando apenas seus lucros.
\end{abstract}

Palavras-chave: Cooperativismo. Sistema Financeiro. Vantagem Competitiva.

\section{The Cooperative and Competitive Advantage: \\ An Analysis of Cooperative Societies and the Commercial Banks}

\begin{abstract}
Currently the company is going through constant transformations of social nature, economic and political because of the globalization process in which we operate. With this the competitiveness between markets will become even more fierce. Within the financial market there are two types of companies offering the same products and services, but with very different profiles: cooperative societies
\end{abstract}


O Cooperativismo como vantagem Competitiva: Uma Análise entre as Sociedades Cooperativas e os Bancos Comerciais

Ana Carolina C. L. da Silva / Ana Paula Ferreira da Costa

Artigo de Demanda Contínua

focusing on social welfare and human capital and commercial banks seeking only their profits.

Keywords: Cooperatives. Financial System. Competitive Advantage.

\section{Introdução}

Dentro do atual cenário em que os mercados estão inseridos, o fenômeno da globalização proporcionou maior acesso do consumidor a novos produtos e serviços. Gerando uma maior necessidade de crédito e assim uma maior competitividade no mercado financeiro.

A necessidade de acesso ao crédito vem desde a antiguidade onde já se buscavam formas de adquirir produtos e serviços. Com o surgimento da moeda surgiram também os primeiros bancos.

A revolução industrial foi o fato que impulsionou o surgimento das primeiras cooperativas que eram de consumo, cujo objetivo era suprir suas necessidades e fugir da exploração da mão-de-obra. Com base nessas cooperativas o italiano Luigi Luzzatti fundou a primeira cooperativa de crédito no ano de 1865 com objetivo ofertar crédito mais barato que os bancos da época

Atualmente, enquanto os bancos em sua maioria,visam a o final de cada exercício lucros exponenciais em seus balanços, as cooperativas de crédito seguem, apresentando modestas sobras, porém, não deixando de oferecer a seus associados, produtos e serviços similares aos bancários com preços e tarifas altamente competitivos.

O presente artigo visa comparar essas duas formas societárias, cooperativas de crédito e bancos em contrapartida ao fenômeno que potencializa esses reflexos: a Globalização.

\section{Revisão de literatura}

\section{Surgimentos dos Bancos e das Cooperativas}

Desde a antiguidade várias formas de cooperação foram experimentadas entre os homens. O cooperativismo moderno, no entanto, na forma como hoje são conhecidas, as sociedades cooperativas, iniciou se em 1844, na cidade inglesa de Rochdale Manchester, quando 28 tecelões fundaram uma cooperativa de consumo, com o objetivo de se contrapor à exploração de mão-de-obra durante a revolução industrial, o cooperativismo se desenvolveu de forma extraordinária em todo o mundo.

Pinho (1982, p. 8) diz que:

“A cooperação quando organizada segundo estatutos previamente estabelecidos, dá origem a determinados grupos sociais. Dentre tais grupos as cooperativas representam aqueles que visam, em primeiro lugar, fins econômicos e educativos". 
O Cooperativismo como vantagem Competitiva: Uma Análise entre as Sociedades Cooperativas e os Bancos Comerciais

Ana Carolina C. L. da Silva / Ana Paula Ferreira da Costa

Artigo de Demanda Contínua

Etimologicamente cooperação (do verbo latino cooperari, de cum e operari $=$ operar junto com alguém) significa a prestação de auxílio para um fim comum. E cooperativismo é a doutrina que visa à renovação social através da cooperação é uma forma de integração social e pode ser entendida como ação conjugada em que pessoas se unem de modo formal ou informal, para alcançar o mesmo objetivo.

Inicialmente, o movimento cooperativista estava subordinado a diversas correntes ideológicas defendidas por intelectuais que influenciavam o pensamento da época, e encontravam no cooperativismo uma saída para os impasses gerados pelo capitalismo nascente.

Todo o processo de formação de cooperativas como uma alternativa para melhoria da qualidade de vida dos trabalhadores, foi duramente criticado por Marx e seus seguidores, que consideravam estes pensadores como socialistas utópicos, pois não levam em conta a contradição básica da luta de classe. Para os marxistas, as relações sociais são condicionadas pelos fatores econômicos e as transações sociais e políticas têm suas raízes nas transformações operadas no modo de produção e de troca. Daí decorre que as relações humanas são determinadas. No sistema capitalista, pela contradição entre a produção social e a apropriação capitalista. Trata-se, pois, de uma contradição infra-estrutural entre o capital e o trabalho, que não poderia ser solucionada simplesmente através da constituição de cooperativas, posto que estariam imersas neste mesmo sistema, não podendo dele libertar-se.

Em 1847, Friedrich Wilhelm Raiffeisen, natural da Remânia, fundou no povoado de Weyerbusch/Westerwald a primeira associação de apoio para a população rural que, embora não fosse ainda uma cooperativa, serviria de modelo para a futura atividade cooperativista de Raiffeisen. A primeira cooperativa, fundada por ele em 1864, chamava-se Heddesdorfer Darlehenskassenverein (Associação de Caixas de Empréstimos de Heddesdorfer).

As cooperativas fundadas por Raiffeisen, tipicamente rurais, tinham como principais características a responsabilidade ilimitada e solidária dos associados, a singularidade de votos dos sócios, independente do número de quotas-partes, a área de atuação restrita, a ausência de capital social e a não distribuição de sobras, excedentes ou dividendos. Ainda hoje esse tipo de cooperativa é bastante popular na Alemanha.

Herman Schulze foi pioneiro no que tange às cooperativas de crédito urbanas. Em 1856 organizou sua primeira "associação de dinheiro antecipado", uma cooperativa de crédito na cidade alemã de Delitzsch. As cooperativas fundadas por Herman Schulze passariam a ser conhecidas como "cooperativas do tipo Schulze-delitzsch", atualmente conhecidas na Alemanha como bancos populares. Diferenciavam-se das cooperativas do tipo Raiffeisen por preverem o retorno das sobras líquidas proporcionalmente ao capital, por terem área de ativação não-restrita e por remunerarem seus dirigentes.

Inspirado nos pioneiros alemães, o italiano Luigi Luzzatti organizou, em 1866, em Milão, a constituição da primeira cooperativa cujo modelo herdaria seu nome, a do Tipo Luzzatti. As cooperativas criadas com essa denominação tem como principais características a não-exigência de vínculo para a associação, exceto algum limite 
O Cooperativismo como vantagem Competitiva: Uma Análise entre as Sociedades Cooperativas e os Bancos Comerciais

Ana Carolina C. L. da Silva / Ana Paula Ferreira da Costa

Artigo de Demanda Contínua

geográfico (bairro, município, etc.), quadras de capital de pequeno valor, concessão de crédito de pequeno valor sem garantias reais, não remuneração dos dirigentes e responsabilidade limitada ao valor do capital subscrito.

Nas Américas, o jornalista Alphonse Desjardins idealizou a constituição de uma cooperativa com características distintas, embora inspiradas nos modelos preconizados por Raiffeisen, Schutze-Delitzsche e Luzzatti. A primeira cooperativa formada por Desjardins foi à província canadense de Quebec, em 6 de Dezembro de 1900. Esse tipo de cooperativa, que no Brasil, hoje, é conhecida como "cooperativa de crédito mútuo", tem como principal característica a existência de algum vínculo entre os sócios, reunindo grupos homogêneos como os de clubes-trabalhadores de uma mesma fábrica, servidores públicos e outros.

Segundo Luiz Dias Thenório Filho (1999), o cooperativismo de crédito no Brasil nasceu no estado do Rio Grande do Sul, em 28 de dezembro de 1902, quase meio século depois da sua aplicação prática na Inglaterra.

Com a chegada ao Brasil do Padre jesuíta Theodor Amstadt, o cooperativismo de crédito foi se introduzindo por meio do seu trabalho, que, percorrendo a região de colonização alemã do Rio Grande do Sul, levava junto com seu trabalho missionário a doutrina cooperativista. A primeira cooperativa de crédito surgiu no município de Nova Petrópolis (RS), em 1902, baseada no modelo agrícola alemão. A partir dessa iniciativa, o movimento de crédito rural tomou força e se expandiu por todo o país, com destaque para o estado gaúcho que, inclusive, chegou a organizar uma central responsável pela monitoração de todas as singulares. Paralelamente, observou-se também o desenvolvimento, sobretudo nas regiões Sul e Sudeste do país, das cooperativas do tipo Luzzatti, chamadas assim aquelas sociedades baseadas no modelo italiano de crédito cooperativo e que tinham como principal característica a aceitação de todas as característica a aceitação de todas as categorias econômicas em seu quadro social.

Em linhas gerais, as cooperativas de crédito são consideradas como sendo organizações que não visam ao lucro, constituídas para prestar serviços financeiros aos associados, como concessão de crédito, captação de depósitos à vista e a prazo, cheques, prestação de serviços de cobrança, de custódia, de recebimentos e pagamentos por conta de terceiros, além de outras operações.

A seguir trecho da Conferência proferida na Associação dos Agricultores por Theodor Amstadt, Feliz, RS, fevereiro 1900.

"Com a carroça cheia e as animálias (animal de carga) carregadas do futuro de seu pesado trabalho e do resultado de muito suor, o colono se dirige à casa comercial, mas as bugigangas estrangeiras, que recebe em troca, para levar para casa, ele facilmente pode colocar debaixo do braço...

Por isso a queixa, que hoje de ouve com freqüência.

Pelas nossas coisas nada recebemos, porém pelo que compramos devemos pagar o valor duplo ou triplo!

Assim estareis de acordo contigo, se eu vos digo: A dependência econômica, na qual atualmente nos encontramos em relação a outros países, é na verdade uma nova escravatura, que está ameaçando nosso país. 
O Cooperativismo como vantagem Competitiva: Uma Análise entre as Sociedades Cooperativas e os Bancos Comerciais

Ana Carolina C. L. da Silva / Ana Paula Ferreira da Costa

Artigo de Demanda Contínua

Como foi ponto de honra abolir a antiga escravatura, assim agora para o verdadeiro brasileiro constituiu uma questão de brio afastar com mão firme esta nova escravatura do nosso Brasil.

Devemos produzir mais, para exportar mais e importar menos, senão nos endividaremos sempre mais. Prefiramos produtos nacionais aos estrangeiros.

Se uma grande pedra se atravessa no caminho e 20 pessoas querem passar, não o conseguirão, se um por um a procuram remover individualmente.

Mas se as 20 pessoas se unem e fazem força ao mesmo tempo, sob a orientação de um deles, conseguirão solidariamente afastar a pedra e abrir o caminho para todos."

Existem relatos de sistemas financeiros desde a antigüidade, onde os povos fenícios já utilizavam várias formas diferentes de realizar pagamentos, como documentos de créditos.

Na medida em que ocorreu o surgimento da moeda no período das grandes civilizações, começaram a surgir pessoas que ofereciam serviços bancários, porém esses serviços eram bastante pequenos e restritos, sendo inclusive, vistos de forma negativa pela sociedade da época. Com a expansão do comércio no fim da Idade Média, a função passasse a transformar-se em trabalho formal e imprescindível para a sociedade. Nas feiras da Europa Central, quando as pessoas chegavam com valores em ouro para trocar com outro produto, era o banqueiro que fazia a pesagem das moedas, avaliação da autenticidade e qualidade dos metais, em troca de uma comissão.

Mas foi no século XVII, que os bancos se firmaram, com o lançamento do dinheiro de papel (papel-moeda) pelo Banco de Estocolmo.

Nesta época, vários países europeus começaram a produzir sua própria moeda.

Outros tipos de bancos surgiram a partir do século XIX, quando o progresso econômico, provocado pela Revolução Industrial, ajudou na criação do banco industrial, cuja função era de mobilizar grandes somas de dinheiro para auxiliar o desenvolvimento industrial.

Atualmente, os bancos são regulados pelo Banco Central de cada país. O Banco Central possui a função de emitir dinheiro, capturar recursos financeiros e regularem os bancos comerciais e industriais, assim eles estabelecem regras e controlam o sistema financeiro geral de cada país.

Atividades bancárias como a custódia de meios de pagamento e os pagamentos a distância mediante transferência nos quais a entrega de um documento de crédito de determinada importância permitia sua cobrança em outra localidade já eram comuns entre os povos que mantinham comércio no Mediterrâneo. As práticas bancárias eram de praxe na Fenícia, no Egito, na Grécia e em Roma. Na baixa Idade Média, as repúblicas mercantis italianas generalizaram a figura do prestamista como um elemento chave do comércio local e regional.

No renascimento apareceu a letra de câmbio, documento que não só permitia a cobrança de seu próprio valor, mas também podia ser utilizado como forma de pagamento. Foi então que teve início a concessão de créditos, isto é, empréstimos que o banco podia 
O Cooperativismo como vantagem Competitiva: Uma Análise entre as Sociedades Cooperativas e os Bancos Comerciais

Ana Carolina C. L. da Silva / Ana Paula Ferreira da Costa

Artigo de Demanda Contínua

cobrar após um prazo estipulado.

Posteriormente começou a emissão de papel-moeda, lançado pela primeira vez em 1661 pelo Banco de Estocolmo. Essa prática foi limitada por todos os países da Europa. Enquanto o sistema continental europeu usava o método de "giro", pelo qual as transferências de pagamento se efetuavam mediante ordens escritas debitadas na conta do pagador e creditadas na do recebedor, a Grã-Bretanha preferiu o cheque como forma de pagamento. Os dois sistemas se distinguiam por ser o cheque um agente mais rápido na criação de dinheiro bancário, proporcionando assim mais eficiência operacional à economia britânica.

A revolução industrial fez surgir um novo tipo de banco, que dinamizou suas operações para adaptar-se ao progresso econômico. No século XIX, os irmãos Péreire fundaram na França o Crédit Mobilier, primeiro banco industrial do mundo. Suas inovações consistiram principalmente em mobilizar vultosos capitais para o desenvolvimento industrial e assumir funções empresariais onde estas fossem imprescindíveis.

A origem dos bancos centrais ou emissores, cuja finalidade é proporcionar ao país o dinheiro necessário e controlar a capacidade de crédito dos bancos comerciais e industriais, remonta as medidas adotadas pelo governo britânico para enfrentar as crises financeiras do século XIX.

A partir de então, esse tipo de banco se disseminou pela maioria dos países. Além de emitir dinheiro, suas funções são as de banqueiro do Estado, assessor financeiro do governo, guarda e custódia do ouro e das reservas internacionais e execução política monetária do Estado.

Desde fins da década de 1970, ocorreram mudanças revolucionárias nos mercados financeiros internacionais, devido a maior disponibilidade de informações e a rapidez com que estas chegavam aos investidores fez aumentar a participação de novos intermediários financeiros e assim, os bancos viram diminuir o espaço econômico que tradicionalmente lhes eram reservado. A informatização veio permitir uma grande rapidez nas operações de pagamento, cobrança e investimentos entre os pontos mais distantes do planeta e anulou, em parte, as vantagens tradicionais de uma grande rede bancária.

\section{Principais Diferenças entre as Cooperativas e os Bancos}

As cooperativas de crédito possuem enormes diferenças se comparada aos bancos comerciais. $\mathrm{O}$ associado pode perceber isso quando se associa ou realiza alguma operação.

A principal diferença entre essas duas instituições diz respeito ao fato de que os bancos são sociedades de capital, ao passo que as cooperativas são sociedades de pessoas. Isso é sem dúvida, o ponto de partida para as demais diferenças existentes entre as mesmas.

\section{Principais diferenças entre Cooperativas de Crédito e Bancos}


O Cooperativismo como vantagem Competitiva: Uma Análise entre as Sociedades Cooperativas e os Bancos Comerciais

Ana Carolina C. L. da Silva / Ana Paula Ferreira da Costa

Artigo de Demanda Contínua

\begin{tabular}{|c|c|}
\hline BANCOS & COOPERATIVAS DE CRÈDITO \\
\hline São sociedades de capital & São sociedades de pessoas \\
\hline $\begin{array}{l}\text { O poder é exercido na proporção do número de } \\
\text { ações }\end{array}$ & $\begin{array}{l}\text { As decisões têm peso igual para todos, uma } \\
\text { pessoa um voto. }\end{array}$ \\
\hline As deliberações são concentradas & As decisões são partilhadas entre muitos \\
\hline $\begin{array}{l}\text { O administrador é um terceiro (homem de } \\
\text { mercado) }\end{array}$ & O administrador é do meio (cooperativado) \\
\hline O usuário de operações é mero cliente & O usuário é o próprio dono (cooperativado) \\
\hline $\begin{array}{l}\text { O usuário não exerce qualquer influência no } \\
\text { preço dos produtos }\end{array}$ & $\begin{array}{l}\text { O usuário é o próprio dono (cooperativado) toda a } \\
\begin{array}{l}\text { política operacional é decidida por eles } \\
\text { (cooperativados) }\end{array}\end{array}$ \\
\hline Podem tratar distintamente cada usuário & $\begin{array}{l}\text { Não podem distinguir: o que vale para um vale } \\
\text { para todos (lei 5764/71) }\end{array}$ \\
\hline Avançam pela competição & Desenvolvem-se pela cooperação \\
\hline Visam o lucro por excelência & $\begin{array}{l}\text { O lucro está fora de seu objeto (art. } 3 \text { da lei } \\
5764 / 71 \text { ) }\end{array}$ \\
\hline $\begin{array}{l}\text { O resultado é de poucos donos (nada é dividido } \\
\text { com o cliente) }\end{array}$ & $\begin{array}{l}\text { O excedente (sobras) é distribuído entre todos os } \\
\text { usuários na proporção das operações individuais } \\
\text { reduzindo ao máximo o preço pago pelos } \\
\text { cooperativados }\end{array}$ \\
\hline São reguladas pela lei das sociedades anônimas & São reguladas pela lei cooperativista \\
\hline
\end{tabular}

Fonte: Meinen et al $(2002,56)$

O objetivo de uma cooperativa de crédito é desenvolver programas de assistência financeira e de prestação de serviços aos cooperados, com a finalidade de oferecer adequado atendimento às suas necessidades de crédito, contribuindo para torná-los independentes de outras instituições financeiras públicas e privadas.

Conforme dispõe a norma legal específica, trata-se de sociedade de pessoas com forma e natureza jurídica própria, de natureza civil, não sujeitas a falência, constituídas para prestar serviços aos associados.

\section{Vantagem Competitiva das Sociedades Cooperativas}

Vantagem competitiva surge fundamentalmente do valor que uma determinada empresa consegue criar para os seus clientes e que ultrapassa os custos de produção. O termo valor aqui aplicado representa aquilo que os clientes estão dispostos a pagar pelo produto ou serviço; um valor superior resulta da oferta de um produto ou serviço com características percebidas idênticas aos da concorrência mas por um preço mais baixo 
O Cooperativismo como vantagem Competitiva: Uma Análise entre as Sociedades Cooperativas e os Bancos Comerciais

Ana Carolina C. L. da Silva / Ana Paula Ferreira da Costa

Artigo de Demanda Contínua

ou, alternativamente, da oferta de um produto ou serviço com benefícios superiores aos da concorrência que mais do que compensam um preço mais elevado.

Desde 1902, as cooperativas de crédito vêm manifestando sua importância junto ao meio econômico do Brasil e na medida em que promovem a aplicação de seus recursos em favor da própria comunidade onde está localizada.

Com seu foco voltado para o social, as cooperativas tendem a buscar o equilíbrio entre a situação econômica e a social, as cooperativas de crédito são estruturas constituídas de forma democrática e estão baseadas nas necessidades de serviços e produtos financeiros das pessoas, sendo que os benefícios gerados deverão, necessariamente, retornar para seus sócios.

Mesmo tendo um papel fundamental para o desenvolvimento de diversas comunidades e regiões do país, o cooperativismo de crédito ainda possui uma participação muito tímida em relação ao sistema financeiro nacional, de acordo com dados da Organização das Cooperativas do Brasil (OCB), as cooperativas respondem por menos de $3 \%$ do mercado financeiro comercial e a maioria delas está presente em municípios onde os bancos privados não chegam, porém, o próprio governo federal sabendo da importância do cooperativismo de crédito para a inclusão social, o combate a concentração de renda e o acesso ao crédito, tem manifestado seu apoio ao setor. Com a mudança da legislação realizada pelo banco central em 2003, as cooperativas ganharam mais corpo e pretendem se expandir no país. Entre as mudanças está a possibilidade de criar cooperativas de livre adesão, o que na prática significa que qualquer pessoa ou empresa, independente da atividade, pode se unir a uma dessas instituições.

As cooperativas de crédito têm como objetivo o atendimento às demandas de serviços financeiros, que suportam as necessidades de crédito e poupança de seus associados; embora haja foco no financeiro, há de se evidenciar que qualquer que seja a cooperativa, ela está embasada no social, logo, pressupõe-se que em sua gestão haja meta e equilíbrio entre o econômico e o social. Isso se torna claro quando se refere a alguns princípios como é o caso do interesse pela comunidade, formação, informação e educação.

Outra das características do perfil das Cooperativas de Crédito é a pulverização, onde empréstimos, praticamente $56 \%$ dos contratos liberados pelas Cooperativas ficam na faixa de valores até $\mathrm{R} \$ 3.000,00$, beneficiando pequenos empreendedores em diversos municípios brasileiros, apesar dos últimos tempos o mercado estampar um forte apelo para a oferta de credito, as Cooperativas pela sua grande função social e, fundamentada em suas características, possuem uma relação de estreito contato com os seus associados, conferindo desta forma a privilegiada condição de verificar a adequada necessidade de recursos e serviços financeiros de seus associados, assim como sua realidade e capacidade de pagamento, oferecendo credito de forma orientada e produtiva, essas ações permitem que as Cooperativas apresentem níveis muito baixos de inadimplência, afinal o empreendimento é do próprio sócio.

Outro dado relevante é o impacto financeiro que o cooperativismo de crédito gera para a sociedade brasileira. No gráfico abaixo, percebe-se a diferença de juros médios cobrados entre as Cooperativas de Crédito e os Bancos Comerciais das principais fontes de 
O Cooperativismo como vantagem Competitiva: Uma Análise entre as Sociedades Cooperativas e os Bancos Comerciais

Ana Carolina C. L. da Silva / Ana Paula Ferreira da Costa

Artigo de Demanda Contínua

empréstimos demandados pela população, são eles: o cartão de credito, o cheque especial e o credito pessoal.

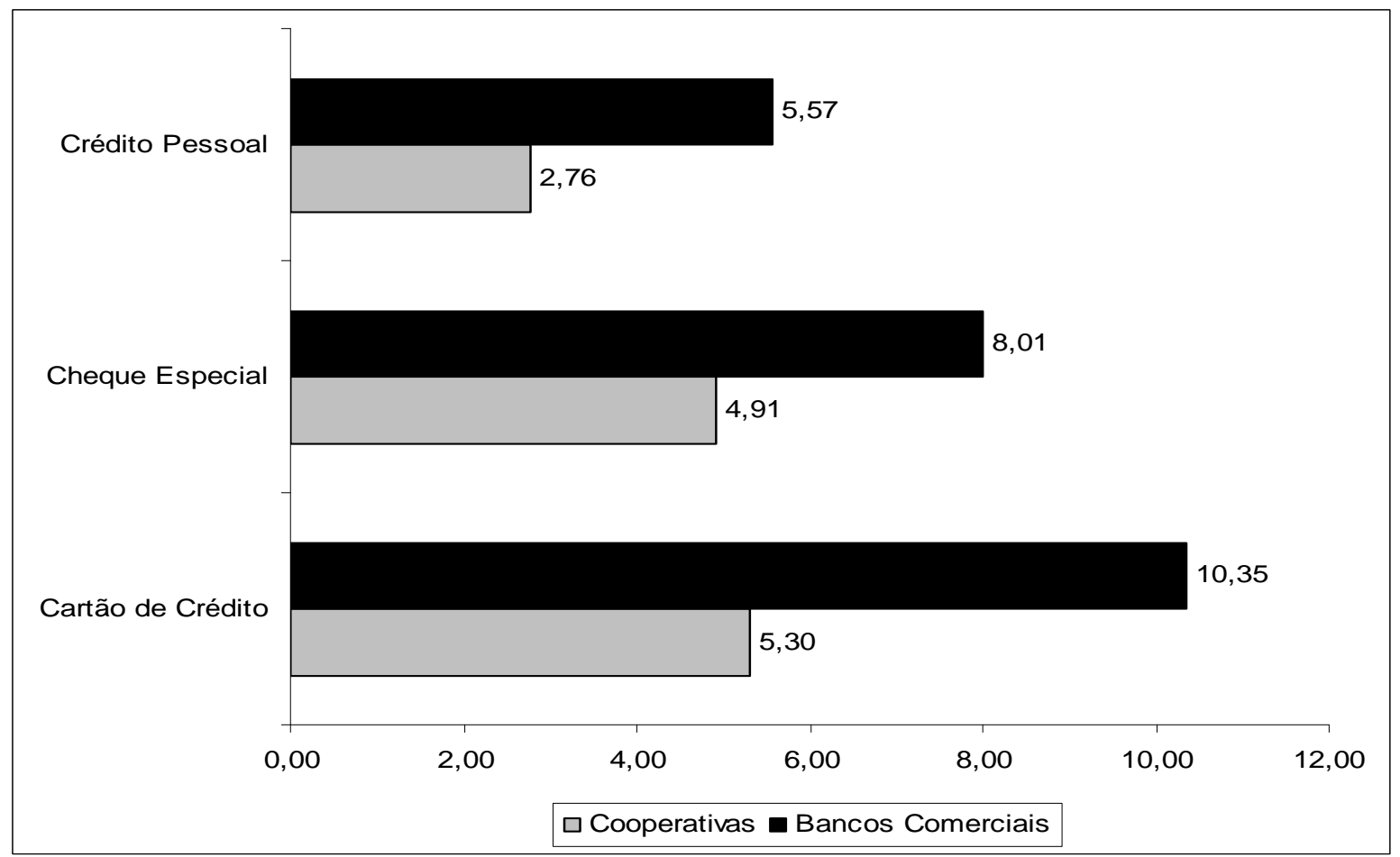

Fonte: OCB (2007)

Tomando como fonte taxas e informações do Banco Central do Brasil, verificou-se que no cartão de crédito a diferença de juros chegou a $5,05 \%$ ao mês, no cheque especial a $3,10 \%$ ao mês e no crédito pessoal a $2,81 \%$ ao mês.

Simulando um comparativo entre os juros que seriam cobrados aos associados de Cooperativas de Crédito, se as mesmas não existissem e essas pessoas tivessem que recorrer aos bancos para tomar os mesmos créditos. Em cartão de credito as Cooperativas possuíam emprestado um montante de mais de $\mathrm{R} \$ 19$ milhões, os associados pagaram às Cooperativos juros na ordem de $\mathrm{R} \$ 1,052$ milhões, o mesmo montante nos bancos resultaria em $\mathrm{R} \$ 2,054$ milhões de juros, logo, uma diferença de $\mathrm{R} \$ 1,001$ milhões em um mês.

Montante Emprestado em Cartão de Crédito: $\mathrm{R} \$ 19.850 .408,00$

Taxas - Juros c/ Coop: 5,30\% a.m. 
O Cooperativismo como vantagem Competitiva: Uma Análise entre as Sociedades Cooperativas e os Bancos Comerciais

Ana Carolina C. L. da Silva / Ana Paula Ferreira da Costa

Artigo de Demanda Contínua

Juros s/ Coop: $10,35 \%$ a.m

Simulação X Juros pagos = Diferença

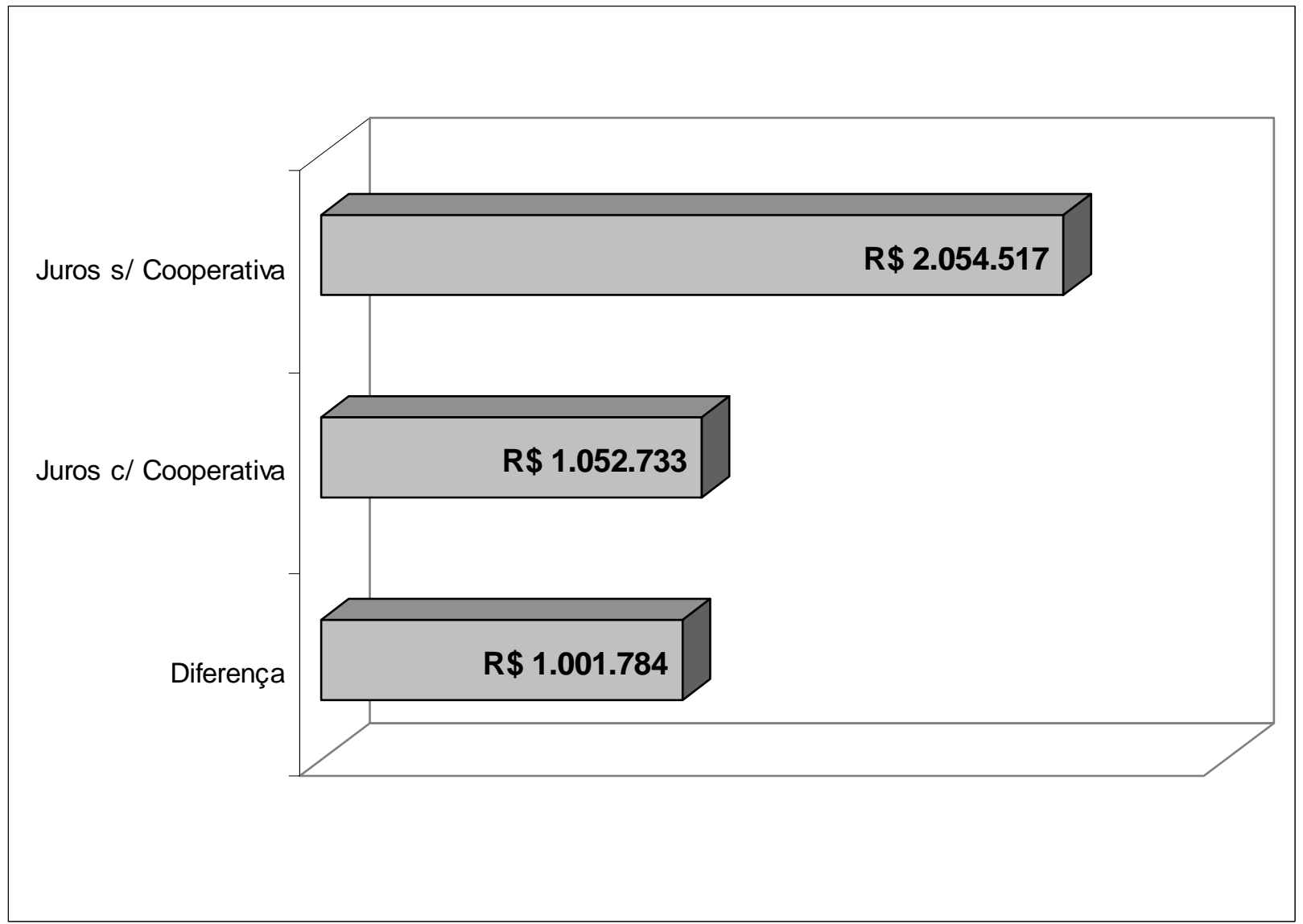

Fonte: OCB (2007)

No cheque especial as Cooperativas possuíam emprestado de seus associados um montante de mais de $\mathrm{R} \$ 508$ milhões, os associados pagaram as Cooperativas juros na casa de R \$24,976 milhões. Se não existissem as cooperativas e os associados precisassem tomar esses valores nos bancos eles pagariam juros na ordem de $\mathrm{R} \$ 40,718$ milhões, desta forma uma diferença de $\mathrm{R} \$ 15,741$ milhões em um mês.

Montante Emprestado em Cheque Especial: R \$ 508.340.144,00

Mosaico - Revista Multidisciplinar de Humanidades, Vassouras, v. 1, n. 2, p. 59-74, jul./dez., 2010 
O Cooperativismo como vantagem Competitiva: Uma Análise entre as Sociedades Cooperativas e os Bancos Comerciais

Ana Carolina C. L. da Silva / Ana Paula Ferreira da Costa

Artigo de Demanda Contínua

Taxas - Juros c/ Coop: 4,91\% a.m

Juros s/ Coop: 8,01\% a.m

Simulação X Juros pagos = Diferença

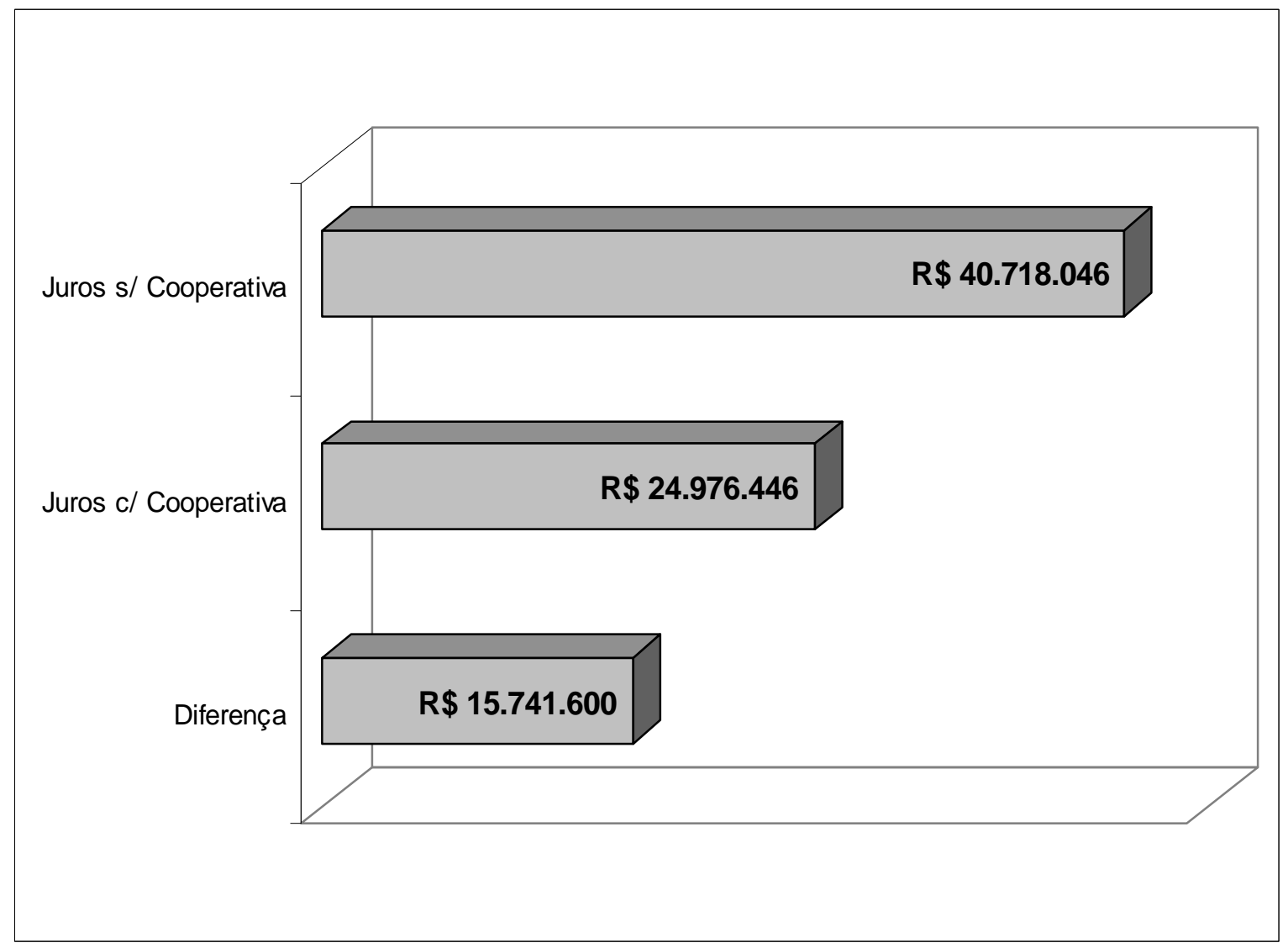

Fonte: OCB (2007)

Com relação ao crédito pessoal, as cooperativas tinham emprestado a seus associados um montante de $\mathrm{R} \$ 4,887$ bilhões. Sendo assim se as cooperativas não emprestassem esses recursos a eles, os mesmos teriam que contrata-los junto aos bancos e pagariam juros ao invés dos $\mathrm{R} \$ 134,9$ milhões as cooperativas, $\mathrm{R} \$ 272,2$ milhões aos bancos, isto remete a uma diferença de $\mathrm{R} \$ 137,3$ milhões em um mês.

Montante Emprestado em Crédito Pessoal: $\mathrm{R} \$ 4.887 .724 .769,00$

Mosaico - Revista Multidisciplinar de Humanidades, Vassouras, v. 1, n. 2, p. 59-74, jul./dez., 2010 
O Cooperativismo como vantagem Competitiva: Uma Análise entre as Sociedades Cooperativas e os Bancos Comerciais

Ana Carolina C. L. da Silva / Ana Paula Ferreira da Costa

Artigo de Demanda Contínua

Taxas - Juros c/ Coop:2,76 \% a.m.

Juros s/ Coop: 5,57\% a.m.

Simulação X Juros pagos = Diferença

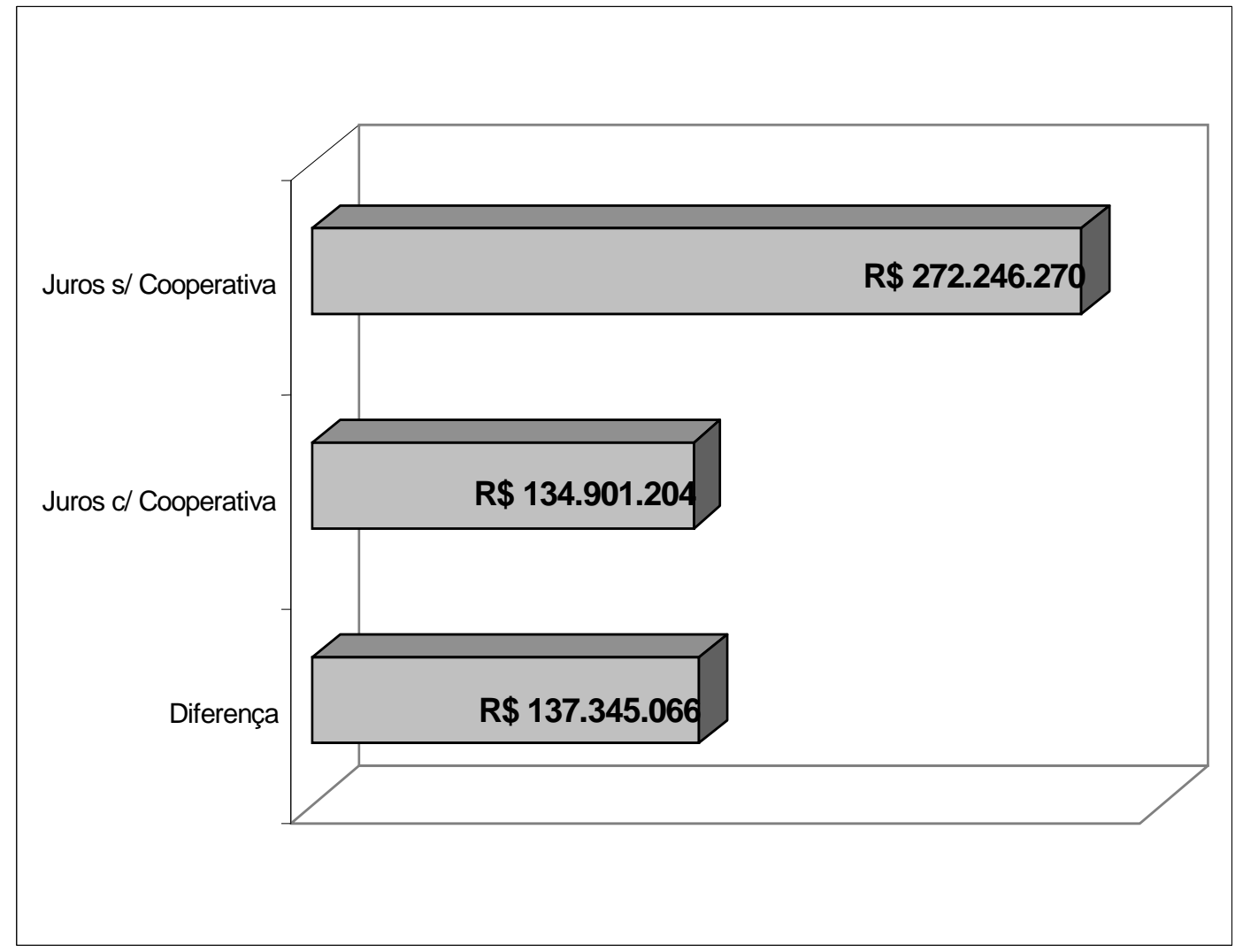

Fonte: OCB (2007)

Com a análise desses três produtos podemos concluir que, a principal bandeira do cooperativismo, que é gerar riqueza na própria comunidade, refletiu de uma forma bastante clara ao passo que fica evidente uma considerável redução de juros cobrados em relação aos bancos que chega a mais de $\mathrm{R} \$ 154$ milhões em apenas um mês, e considerando que este valor foi economizado pelos associados e que os mesmos foram atendidos em sua necessidade de produtos financeiros e ainda puderam pagar bem menos por isso. $\mathrm{O}$ dinheiro eqüivale a $\mathrm{R} \$ 154$ milhões serão utilizados em empreendimentos, consumo e poupança gerando mais divisas e desenvolvimento para a 
O Cooperativismo como vantagem Competitiva: Uma Análise entre as Sociedades Cooperativas e os Bancos Comerciais

Ana Carolina C. L. da Silva / Ana Paula Ferreira da Costa

Artigo de Demanda Contínua

sociedade brasileira.

A participação das cooperativas de crédito hoje oscila em torno de $3 \%$ no Sistema Financeiro nacional, segundo dados do Banco Central do Brasil, e mesmo com esta pequena participação conseguem beneficiar milhares de brasileiros em várias comunidades do interior e dos grandes centros do país, caso elas tivessem uma participação maior certamente os benefícios seriam proporcionais; apenas para constatação, a participação dos bancos estrangeiros no Sistema Financeiro do país supera os $20 \%$.

A realidade do Brasil é bem diferente do que se encontra em países desenvolvidos. Em países desenvolvidos o papel dos bancos cooperativos é fundamental para todo o continente Europeu, atingindo cerca de 130 milhões de clientes, 700 mil empregos, 60 mil agências e 17\% dos depósitos financeiros, destaques para a França, Holanda, Espanha e Alemanha. Nos Estados Unidos a performance do cooperativismo de crédito também impressiona pelos seus números, pois são mais de 85 milhões de associados, 661 bilhões de dólares de ativos, 423 bilhões de dólares de empréstimos e mais de 570 bilhões de dólares de depósitos.

No atual cenário em que vivemos, o fenômeno conhecido como Globalização ( nome genérico dado às transformações ocorridas mundialmente no período recente nos campos comercial, produtivo e financeiro e visando a valorização do mercado e menor participação do Estado) faz se cada vez mais presente em nosso dia-a-dia, principalmente no que tange ao mercado financeiro, que saiu das mãos dos bancos e deu mais poder de fogo aos especuladores. A globalização possui ramificações industriais, de prestação de serviços, comerciais ou financeiras, graças a queda do custo da comunicação e as novas tecnologias de troca de dados. Do ponto de vista tecnológico a velocidade da informação, o barateamento e confiabilidade são as principais características da globalização.

O desemprego é um drama dos países mais pobres, que perdem com a desvalorização das matérias-primas que exportam e o atraso tecnológico. A globalização não beneficia a todos de maneira uniforme. Uns ganham muito, outros ganham menos, outros perdem. Exigem-se menores custos de produção e maior tecnologia. A mão-de-obra menos qualificada é descartada. A globalização está concentrando renda, os países ricos ficam mais ricos, e os pobres mais pobres, e os motivos são diversos entre eles, subsidiar os produtos agrícolas nos países ricos, inviabiliza os pobres, além de outros motivo econômicos.

\section{Considerações Finais}

Diante do cenário econômico altamente globalizado, as cooperativas vem demonstrando que tem capacidade de competir com os bancos comerciais.

No que se refere a vantagem competitiva, as cooperativas se destacam pois seu foco está no capital humano, no lado social de unir as pessoas com a intenção de atingir um único objetivo. Como as cooperativas não têm o objetivo de ter lucro no final do exercício e 
O Cooperativismo como vantagem Competitiva: Uma Análise entre as Sociedades Cooperativas e os Bancos Comerciais

Ana Carolina C. L. da Silva / Ana Paula Ferreira da Costa

Artigo de Demanda Contínua

sim de sobras, que são rateadas proporcionalmente para cada associado que aplicou na cooperativa, isso faz com que as cooperativas possuam taxas mais competitivas do que as de um banco comercial. As cooperativas tem a possibilidade de oferecer crédito mais barato para o povo, atendendo as suas necessidades de forma que proporcione o seu crescimento.

Finalmente, parafraseando Friedman (2005), devido ao aumento exponencial da velocidade das informações, seguido de uma constante capacidade de assimilação por parte dos atores envolvidos, a globalização se torna o divisor de águas para a propagação de inúmeros conceitos e idéias.

Por extensão entendemos que tal estado da arte é fundamental para a difusão, compreensão e assimilação dos princípios e preceitos cooperativistas, fazendo com que os mesmos cheguem a todas as camadas da população em um tempo antes improvável ou mesmo inimaginável. 
O Cooperativismo como vantagem Competitiva: Uma Análise entre as Sociedades Cooperativas e os Bancos Comerciais

Ana Carolina C. L. da Silva / Ana Paula Ferreira da Costa

Artigo de Demanda Contínua

\section{Referências}

Aktouf, O. Pós-globalização, Administração e Racionalidade Econômica. Editora Atlas, 2004

Cartilha do Curso Básico de Cooperativismo. Sescoop/DF, p.08, 2007.

Filho, L. D. T. Pelos Caminhos do Cooperativismo com Destino ao Crédito Mútuo. $1^{\mathrm{a}}$ ed., Editora Confebrás, 1999.

Friedman, T. L. O Mundo é Plano, uma breve história do Século XXI. Editora Objetiva, 2005.

Gonçalves, L. S. M. Cooperativa de Crédito Luzzatti de Mendes - História, Gestão e Modelo de Livre Adesão. Resistência Pacífica, União e Vitória. Ed. Confebrás, 2005.

Meinem, E. Aspectos Jurídicos do Cooperativismo. Editora Confebrás, 2002

Pinheiro, M. A. H. Cooperativismo de Crédito, História da Evolução Normativa no Brasil. $5^{\text {a }}$ ed., Banco Central, 2007.

www.bcb.gov.br. Acessado em 15/10/2008

www.brasilcooperativo.coop.br. Acessado em 08/10/2008

www.ocb.org.br. Acessado em 15/10/2008 